\title{
DSP-Based Sensor Fault Detection and Post Fault-Tolerant Control of an Induction Motor-Based Electric Vehicle
}

\author{
Bekheïra Tabbache, ${ }^{1,2}$ Mohamed Benbouzid,' \\ Abdelaziz Kheloui, ${ }^{2}$ and Jean-Matthieu Bourgeot ${ }^{3}$ \\ ${ }^{1}$ University of Brest, EA 4325 LBMS, rue de Kergoat, CS 93837, 29238 Brest Cedex 03, France \\ ${ }^{2}$ Ecole Militaire Polytechnique, UER ELT, Algiers 16111, Algeria \\ ${ }^{3}$ ENIB, EA 4325 LBMS, 945, Avenue Technopole, 29280 Plouzané, France \\ Correspondence should be addressed to Mohamed Benbouzid, mohamed.benbouzid@univ-brest.fr
}

Received 29 August 2012; Revised 22 October 2012; Accepted 15 November 2012

Academic Editor: Tee Cheng

Copyright (๑) 2012 Bekheïra Tabbache et al. This is an open access article distributed under the Creative Commons Attribution License, which permits unrestricted use, distribution, and reproduction in any medium, provided the original work is properly cited.

This paper deals with sensor fault detection within a reconfigurable direct torque control of an induction motor-based electric vehicle. The proposed strategy concerns current, voltage, and speed sensors faults that are detected and followed by post faulttolerant control to allow the vehicle continuous operation. The proposed approach is validated through experiments on an induction motor drive and simulations on an electric vehicle using a European urban and extraurban driving cycle.

\section{Introduction}

Fault tolerance is gaining interest as a means to increase the reliability, the availability, and the continuous operation of electromechanical systems among them automotive ones [1, 2 ]. In the automotive context, electric vehicle is a key application where the propulsion control depends on the availability and the quality of sensor measurements. Measurements, however, can be corrupted or interrupted due to sensor faults. If some sensors are missing, the controllers cannot provide the correct control actions for the EV propulsion. It is therefore compulsory to have a sensor fault detection and isolation system to improve the reliability of the electric drive. Thereafter, reconfiguration should be achieved with equivalent observed signals. This will allow fault-tolerant operation.

In this context, an FTC approach is proposed for an induction motor-based EV experiencing sensor faults (current, voltage, and speed) $[3,4]$. As DTC is recognized as a high-performance control strategy for EVs electric propulsion, it has been adopted $[5,6]$. In general, DTC-based induction motor drives use two current sensors, one or two voltage sensors, and a speed sensor.

For sensor fault tolerance purposes, the tendency is to use three currents sensors and introduce observers and estimation techniques to detect and isolate current and speed sensor faults [6-12]. Some proposed FTC approaches use three nonlinear observers to guarantee the information redundancy [9]. Unfortunately, multiple observer schemes cannot be so easily implemented due to the limited sampling period even with recently developed DSPs. In [9], a Luenberger observer is used to estimate the speed and generates residuals. Unfortunately, even if this observer gives good results, the obtained performances in case of induction motors are proven to be limited in particular at low speed. This is mainly due to the induction motor strong nonlinearity.

The proposed FTC approach, which is based on a bank of observers, the Extended Kalman Filter is adopted for the estimation of the stator flux, the speed, and the generation of the current and speed residuals for fault detection and replacement signals for the reconfiguration. To 


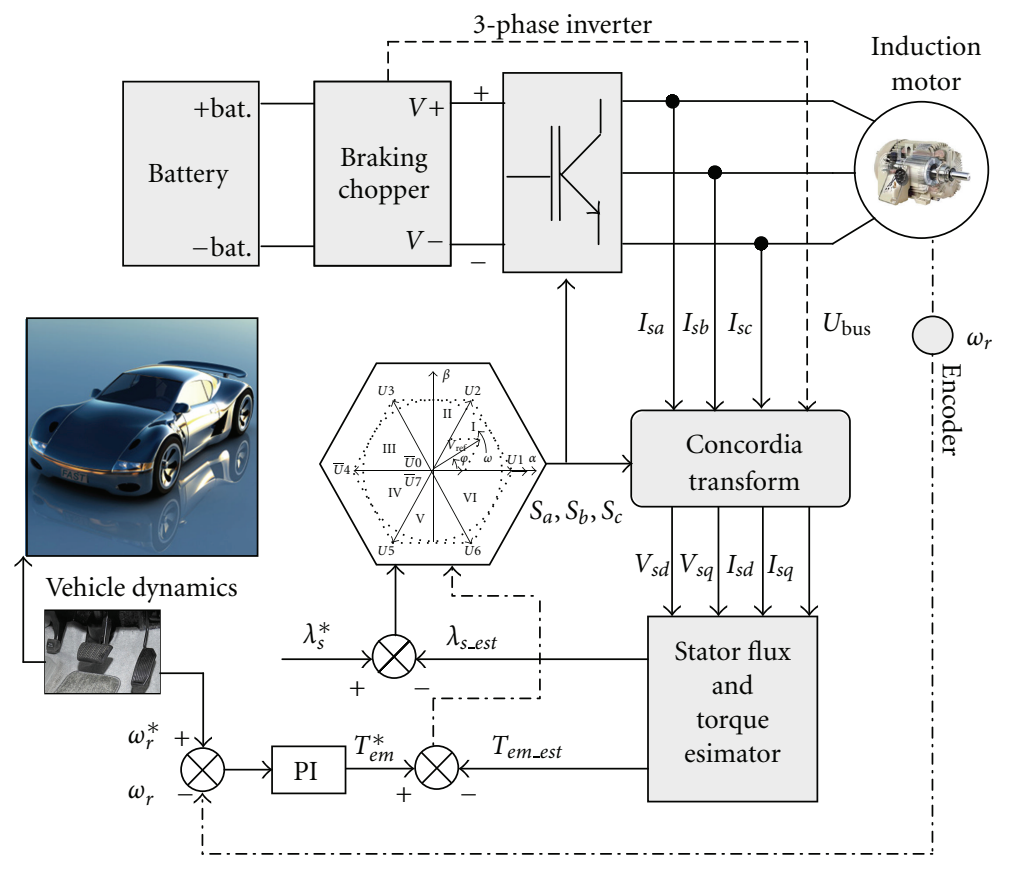

Figure 1: DTC block diagram.

detect and isolate sensor faults, nonlinear observers are used to guarantee the redundancy [10].

\section{Induction Motor-Based EV DTC Briefly}

The basic idea of the method is to calculate flux and torque instantaneous values only from the stator variables. Flux, torque, and speed are estimated. The input of the motor controller is the reference speed, which is directly applied by the pedal of the vehicle. Control is carriedout by hysteresis comparators and a switching logic table selecting the appropriate voltage inverter switching configurations [5].

Figure 1 gives the global configuration of a DTC scheme and also shows how the EV dynamics is taken into account.

\section{Sensor Fault Detection and Isolation}

Sensor fault detection and isolation (SFDI) is based on two parts. The first one generates sensor residuals. The second part detects and isolates the faulty sensors (current, voltage, or speed sensors).

3.1. EKF for Residual Generation. In our case, only one observer, the EKF for instance, has been adopted.

The Kalman filter is a special class of linear observer (deterministic type), derived to meet a particular optimality stochastic condition.

The Kalman filter has two forms: basic and extended. The EKF can be used for nonlinear systems where the plant model is extended by extravariables, in our case by the mechanical speed [13].

In an induction motor drive, the Kalman filter is used to obtain unmeasured state variables (rotor speed $\omega_{r}$, rotor flux vector components $\lambda_{r \alpha}$, and $\lambda_{r \beta}$ ) using the measured state variables (stator current $i_{s}$ and voltage components $V_{s}$ in the Concordia frame $\alpha-\beta$ ). Moreover, it takes into account the model and measurement noises.

The induction motor state model used by the EKF is developed in the stationary reference frame and summarized by (1) $[5,14]$, where $R$ is the resistance, $L$ is the inductance, and $L_{m}$ is the magnetizing inductance.

The implementation of the Kalman filter is based on a recursive algorithm minimizing the error variance between the real variable and its estimate

$$
\begin{aligned}
& \frac{d}{d t}\left[\begin{array}{c}
i_{s \alpha} \\
i_{s \beta} \\
\lambda_{r \alpha} \\
\lambda_{r \beta} \\
\omega_{r}
\end{array}\right]=\left[\begin{array}{ccccc}
-\frac{K_{R}}{K_{L}} & 0 & \frac{L_{m} R_{r}}{L_{r}^{2} K_{L}} & \frac{L_{m} \omega_{r}}{L_{r} K_{L}} & 0 \\
0 & -\frac{K_{R}}{K_{L}} & \frac{L_{m} \omega_{r}}{L_{r} K_{L}} & \frac{L_{m} R_{r}}{L_{r}^{2} K_{L}} & 0 \\
\frac{L_{m}}{T_{r}} & 0 & -\frac{1}{T_{r}} & -\omega_{r} & 0 \\
0 & \frac{L_{m}}{T_{r}} & \omega_{r} & -\frac{1}{T_{r}} & 0 \\
0 & 0 & 0 & 0 & 1
\end{array}\right]\left[\begin{array}{c}
i_{s \alpha} \\
i_{s \beta} \\
\lambda_{r \alpha} \\
\lambda_{r \beta} \\
\omega_{r}
\end{array}\right] \\
& +\frac{1}{K_{L}}\left[\begin{array}{ll}
1 & 0 \\
0 & 1 \\
0 & 0 \\
0 & 0 \\
0 & 0
\end{array}\right]\left[\begin{array}{c}
V_{s \alpha} \\
V_{s \beta}
\end{array}\right] \\
& {\left[\begin{array}{c}
i_{s \alpha} \\
i_{s \beta}
\end{array}\right]=\left[\begin{array}{lllll}
1 & 0 & 0 & 0 & 0 \\
0 & 1 & 0 & 0 & 0
\end{array}\right]\left[\begin{array}{c}
i_{s \alpha} \\
i_{s \beta} \\
\lambda_{r \alpha} \\
\lambda_{r \beta} \\
\omega_{r}
\end{array}\right],}
\end{aligned}
$$

where $K_{L} / K_{R}=R_{s} / L_{s}+1-\sigma / \sigma T_{r}, T_{r}=L_{r} / R_{r}, T_{s}=L_{s} / R_{s}$, and $\sigma=1-L_{m}^{2} / L_{s} L_{r}$. 
Let us consider a linear stochastic system whose discrete state model is given by

$$
\begin{gathered}
x(k+1)=A x(k)+B u(k)+w(k), \\
y(k+1)=C x(k)+v(k),
\end{gathered}
$$

where $w(k)$ represents the disturbances vector applied to the system inputs. It also represents the modeling uncertainties; $v(k)$ corresponds to system output measurement noises. It is supposed that the random signals $v(k)$ and $w(k)$ are Gaussian noises not correlated and with null average value. They are characterized by covariance matrixes, $Q$ and $R$, respectively, which are symmetrical and positive definite. The initial state vector $x_{0}$ is also a random variable with covariance matrix $P_{0}$ and average value $\bar{x}_{0}$.

The Kalman filter recursive algorithm is illustrated by Figure 2. For an induction motor, the Kalman filter must be used in its extended version. Therefore, a nonlinear stochastic system discrete state equation is given by

$$
\begin{gathered}
x_{k+1}=f\left(x_{k}, u_{k}\right)+w_{k}, \\
y_{k}=h\left(x_{k}\right)+v_{k},
\end{gathered}
$$

where $f$ and $h$ are vector functions

$$
f=\left[\begin{array}{c}
\left(1-T \frac{K_{R}}{K_{L}}\right) i_{s \alpha}+T \frac{L_{m} R_{r}}{L_{r}^{2} K_{1}} \lambda_{r \alpha}+T \frac{L_{m} \omega_{r}}{L_{r} K_{L}} \lambda_{r \beta}+T \frac{1}{K_{L}} V_{s \alpha} \\
\left(1-T \frac{K_{R}}{K_{L}}\right) i_{s \beta}-T \frac{L_{m} R_{r}}{L_{r}^{2} K_{1}} \lambda_{r \alpha}+T \frac{L_{m} \omega_{r}}{L_{r} K_{L}} \lambda_{r \beta}+T \frac{1}{K_{L}} V_{s \beta} \\
T \frac{L_{m}}{T_{r}} i_{s \alpha}+\left(1-T \frac{1}{T_{r}}\right) \lambda_{r \alpha}-T \omega_{r} \lambda_{r \beta} \\
T \frac{L_{m}}{T_{r}} i_{s \beta}+T \omega_{r} \lambda_{r \alpha}+\left(1-T \frac{1}{T_{r}}\right) \lambda_{r \beta} \\
\omega_{r} \\
h=C_{d} x_{k \mid k+1}=\left[\begin{array}{c}
i_{s \alpha} \\
i_{s \beta}
\end{array}\right] .
\end{array},\right.
$$

The notation $k+1$ is related to predicted values at $(k+1)$ th instant and is based on measurements up to $k$ th instant. $T$ is the sampling period.

The EKF equations are similar to those of the linear Kalman filter with the difference that $A$ and $C$ matrices should be replaced by the Jacobians of the vector functions $f$ and $h$ at every sampling time as follows:

$$
\begin{aligned}
& A_{k}[i, j]=\left.\frac{\partial f_{i}}{\partial x_{j}}\right|_{x=\hat{x}(k \mid k)}, \\
& C_{k}[i, j]=\left.\frac{\partial h_{i}}{\partial x_{j}}\right|_{x=\hat{x}(k \mid k-1)} .
\end{aligned}
$$

The covariance matrices $R_{k}$ and $Q_{k}$ are also defined at every sampling time.

For the induction motor control, the EKF is used for the speed real-time estimation. It can also be used to estimate states and parameters using the motor voltages and currents measurements.

\subsection{Sensor Fault Detection and Isolation}

3.2.1. Current Sensor Faults. Three sensors are used to measure the motor currents. To detect current sensor faults, the following equation is used:

$$
i_{\text {sum }}=i_{a s}^{m}+i_{b s}^{m}+i_{c s}^{m},
$$

where the upper script $m$ means a measured quantity.

Indeed, if one or two sensors fail, $i_{\text {sum }}$ will be a nonzero sinusoidal signal. Therefore, additional logic and information (redundancy) are required to isolate the failed sensor. The required redundancy can be obtained from the EKF which is driven by the scheduled test input sets

$$
\begin{aligned}
& \operatorname{CSFI}(1)=\left\{i_{a s}^{m}, i_{b s}^{m}, i_{c s}^{m 1}\right\} \quad \text { when } i_{c s}^{m 1}=-\left(i_{a s}^{m}+i_{b s}^{m}\right), \\
& \operatorname{CSFI}(2)=\left\{i_{a s}^{m}, i_{b s}^{m 2}, i_{c s}^{m}\right\} \quad \text { when } i_{b s}^{m 2}=-\left(i_{a s}^{m}+i_{c s}^{m}\right),
\end{aligned}
$$

where CSFI is the Current Sensor Fault Isolation input for phase a or b. CSFI(1) is used to isolate a faulty current sensor in phase $c$ and $\operatorname{CSFI}(2)$ to isolate a faulty current sensor in phase a or b. It should be noticed that the two current residuals are calculated using Concordia components to isolate the faulty current sensor.

Sensor fault detection is performed using $i_{\text {sum }}$. The first residue is calculated using the Concordia currents provided by $\operatorname{CSFI}(1)$

$$
r_{1}=\left|i_{s \alpha}^{m 1}-\hat{i}_{s \alpha}\right|+\left|i_{s \beta}^{m 1}-\hat{i}_{s \beta}\right| .
$$

If this residue is lower than a predefined threshold, current sensor (c) should be the failed one. Otherwise, the fault sensors are (a) or (b). In this case, an additional residue is calculated using $\operatorname{CSFI}(2)$

$$
r_{2}=\left|i_{s \alpha}^{m 2}-\hat{i}_{s \alpha}\right|+\left|i_{s \beta}^{m 2}-\hat{i}_{s \beta}\right| .
$$

If this residue is greater than a predefined threshold, the faulty current sensor is (a). Otherwise, it is (b). The estimated currents $\left({ }^{\wedge}\right)$ are provided by the EKF.

It should be noted that the proposed fault detection method avoid merging CSFI(1) and CSFI(2) information.

3.2.2. Voltages Sensor Faults. The fault detection may be performed using a simple threshold test on the parity equation (10), which describes the three-phase simple voltage equivalence

$$
V_{\text {sum }}=V_{a s}^{m}+V_{b s}^{m}+V_{c s}^{m} .
$$

It is used to monitor the EKF inputs and therefore ensure the efficient operation of the proposed FTC.

3.2.3. Speed Sensor Faults. The fault detection is achieved by comparing the measured speed with the estimated one given by the EKF. The encoder fault detection is given by the following residual:

$$
r_{\emptyset}=\left|\omega_{m}^{m}-\widehat{\omega}_{m}^{m}\right| .
$$

Figure 3 illustrates the SFDI principle. It includes the EKF, the residual generation, and the Concordia transforms. 


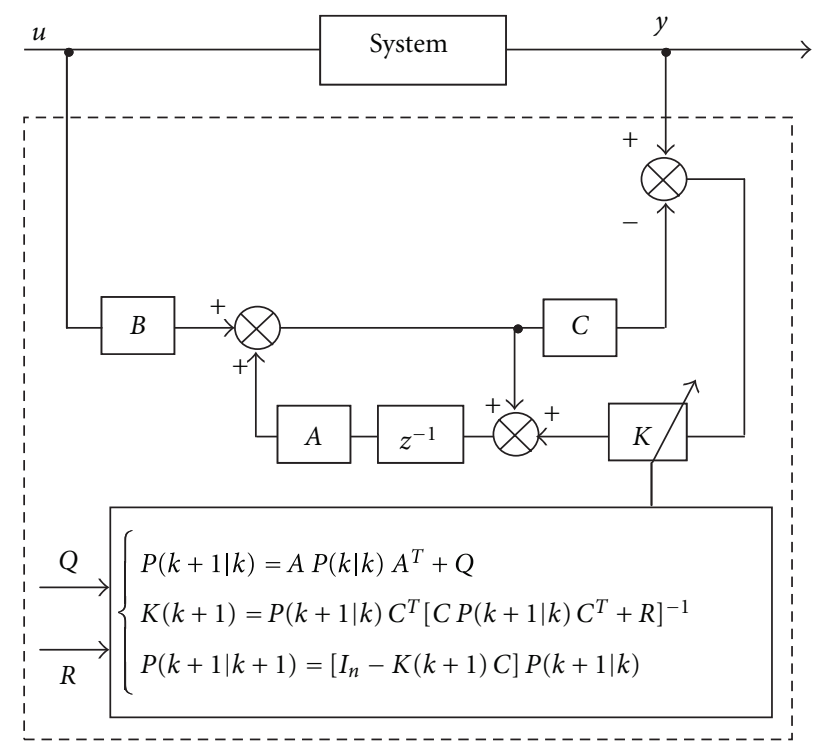

FIgure 2: The Kalman filter recursive algorithm.

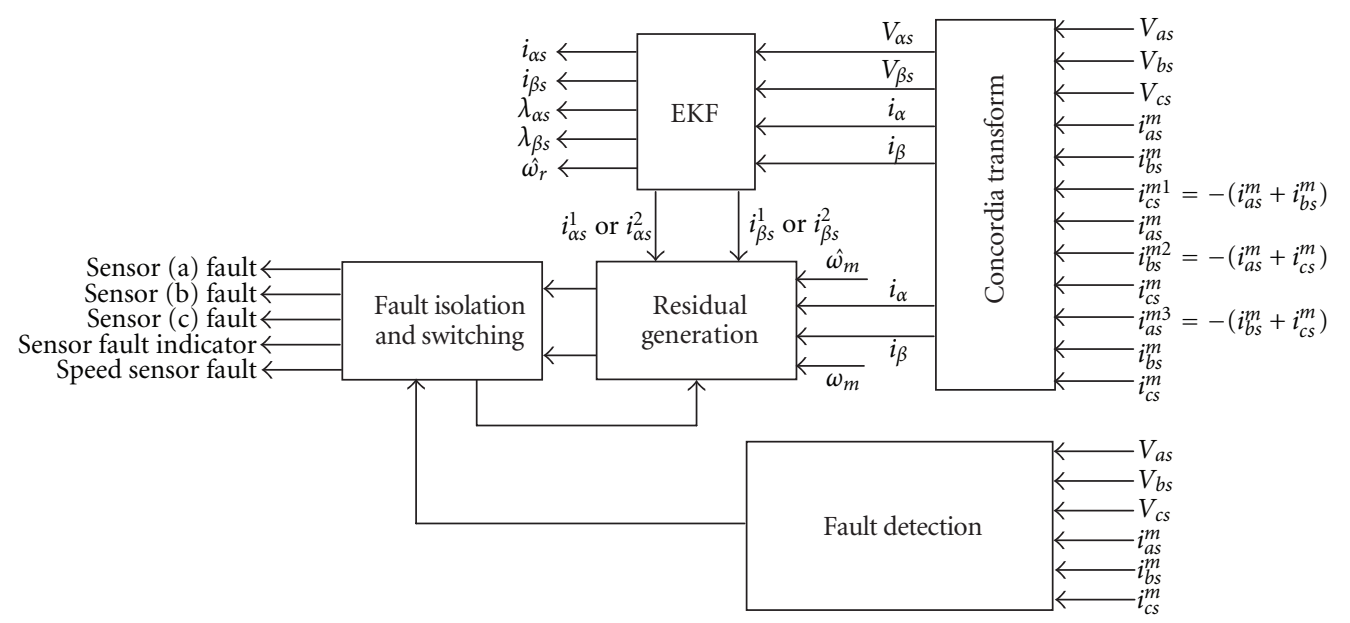

FIGURE 3: Sensor fault detection and isolation scheme.

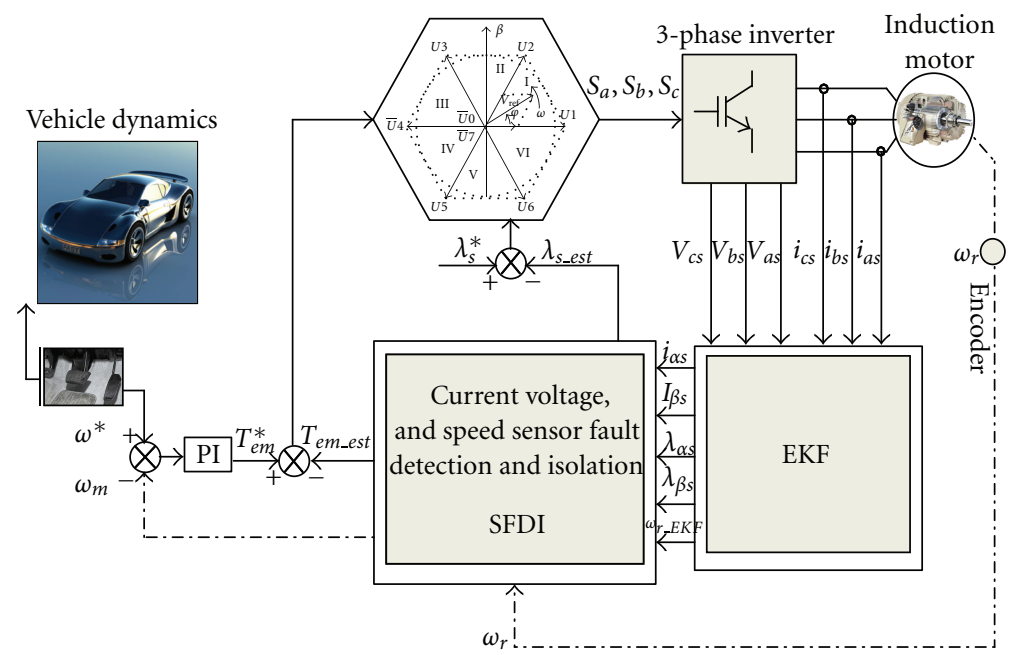

FIgURE 4: The proposed sensor fault-tolerant control scheme. 


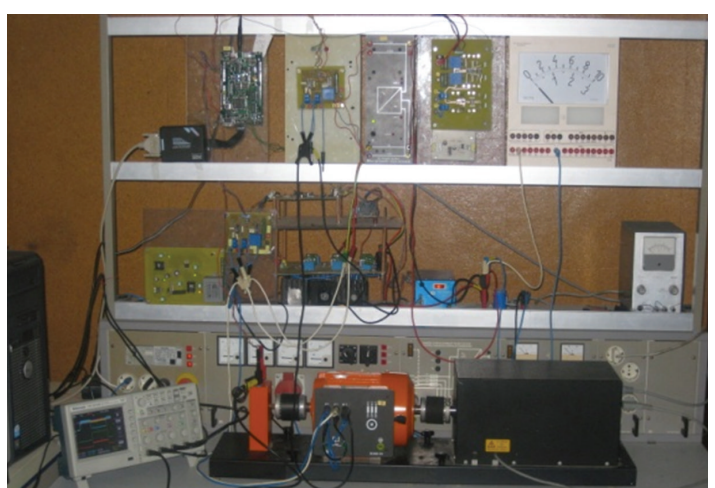

(a)

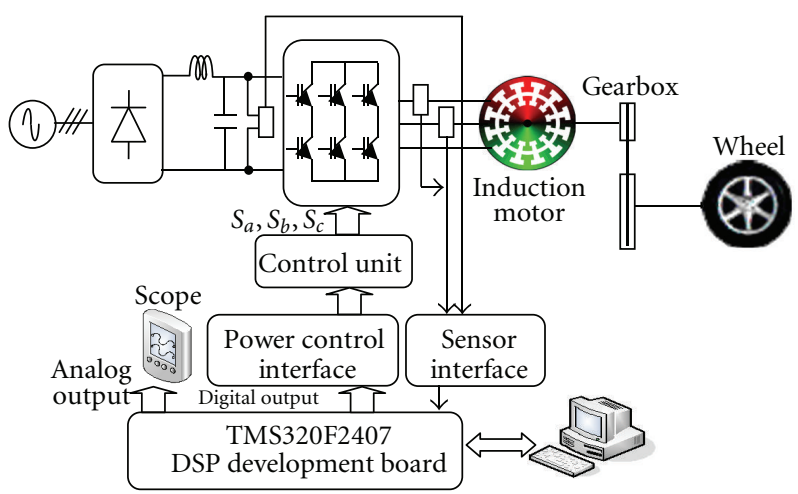

(b)

Figure 5: (a) View and (b) schematic description of the experimental bench.

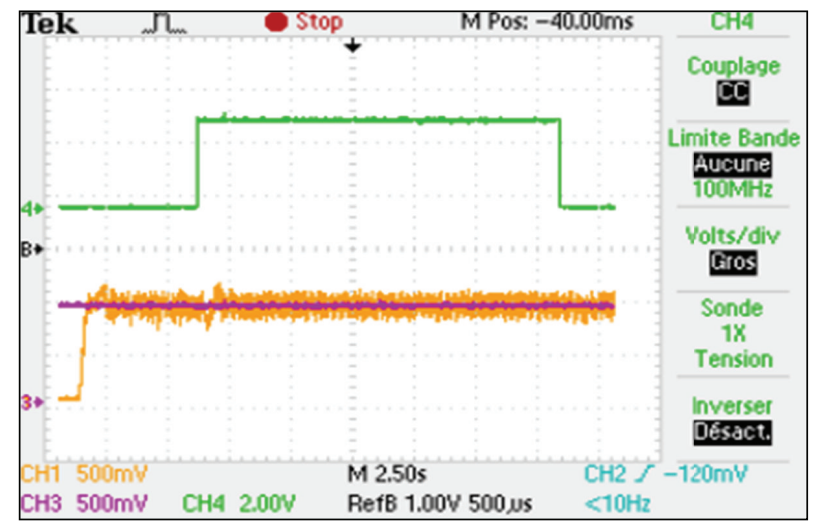

(a) Sensor fault indicator (green), motor speed (orange), reference speed (purple)

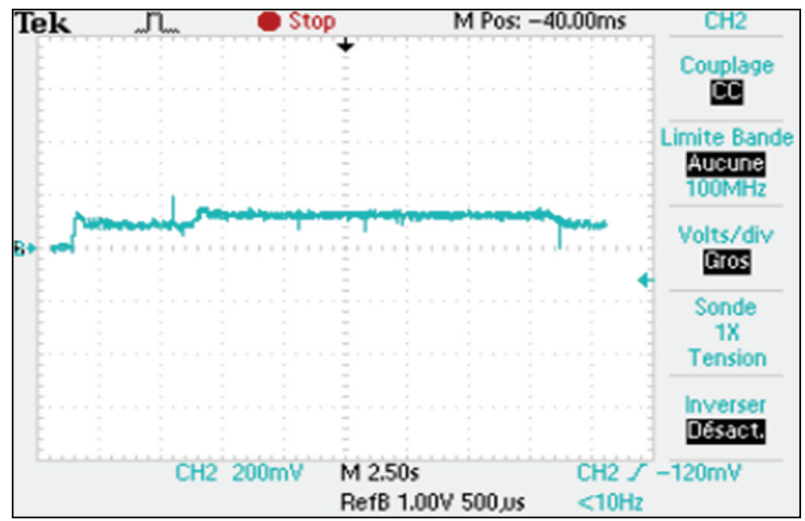

(b) Current residual

FIgURE 6: Induction motor drive FTC performance under a current sensor fault.

3.3. Sensor Fault-Tolerant Control Scheme. Figure 4 describes the proposed fault-tolerant control scheme in terms of current, voltage, and speed sensor faults.

\section{Experimental and Simulation Tests}

4.1. Induction Motor Sensor Fault-Tolerant Control. Experimental tests have been first carriedout to check the sensor fault-tolerant control performances on a $1-\mathrm{kW}$ induction motor drive (Figure 5).

The used cage induction motor rated data are given in the Appendix. This motor is supplied by a 2-level voltage inverter. The setup main components are a DSP system (single fixed-point TMS320LF2407), a speed sensor attached to the motor shaft, current and voltage sensors. The DSP system is interfaced to a standard PC.

Figures 6 and 7 illustrate experimental results for current and speed sensors, respectively. Figure 6 shows the response of the proposed sensor FTC scheme in the event of one current sensor failure (phase b). In this case, the proposed algorithm ensures the control as shown by the speed and its reference in Figure 6(a). Figure 7 shows the sensor FTC performances in the event of a speed sensor failure. In this case, the sensor speed is replaced by the EKF estimates ensuring then the control as illustrated by Figure 7(a).

The obtained results confirm the effectiveness of the proposed sensor fault detection and post fault-tolerant control approach. Indeed, quiet good speed tracking performances are achieved.

4.2. EV Sensor Fault-Tolerant Control. The proposed sensor fault detection and post fault-tolerant control approach is now evaluated for an electric vehicle using a $37-\mathrm{kW}$ induction motor based powertrain. The EV and the used cage induction motor rated data and parameters are given in the Appendix. Simulations are carriedout using a European urban and extraurban driving cycle as speed reference. For that purpose, two sensor faults are introduced: a current sensor fault in phase a (an offset) at 2-sec and a speed sensor fault (a signal disconnection) at 7-sec.

Figure 8 shows the EV fault-tolerant performances in terms of speed (via a single gear). The obtained results clearly confirm the effectiveness of the proposed post fault-tolerant control approach. 


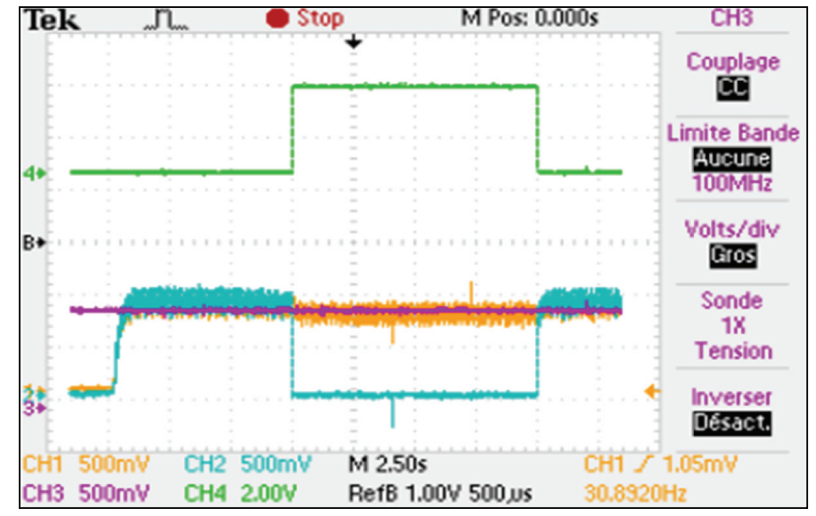

(a) Sensor fault indicator (green), motor speed (orange), speed sensor output (blue), reference speed (purple)

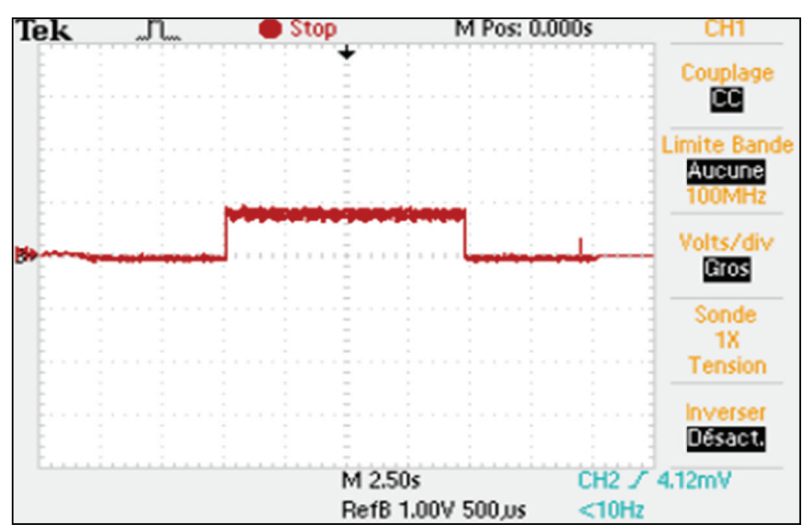

(b) Speed residual

FIGURE 7: Induction motor drive FTC performance under a speed sensor fault.

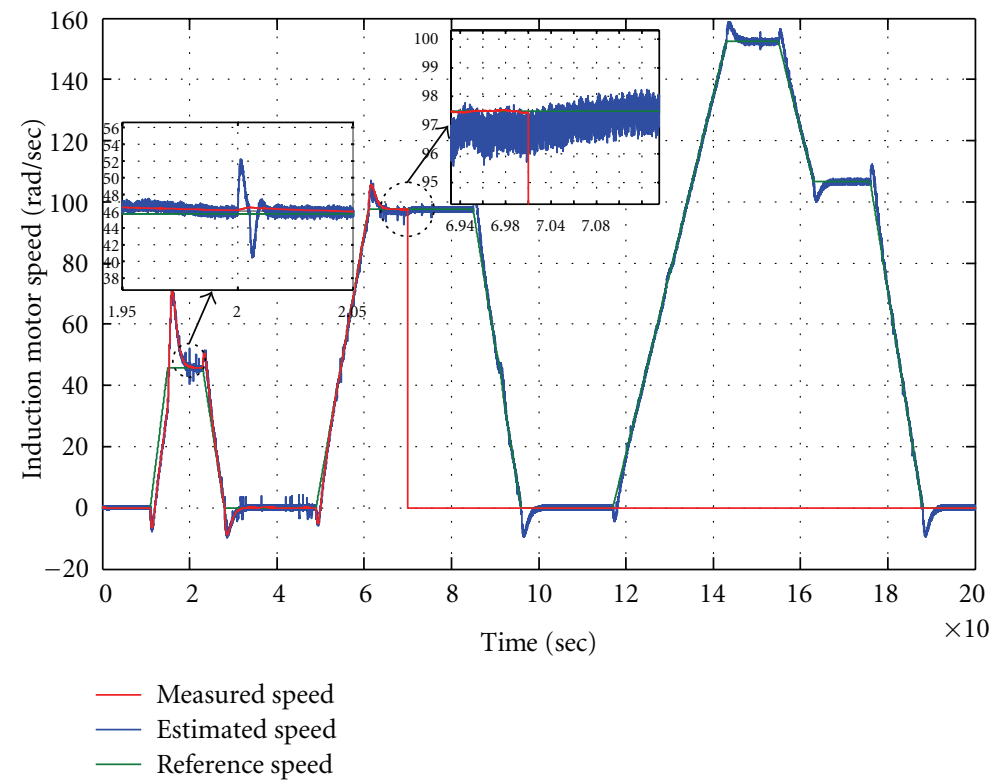

FIGURE 8: EV FTC performances: measured speed (red), estimated speed (blue), and reference speed (green).

\section{Conclusion}

This paper dealt with fault-tolerant control of an induction motor-based EV experiencing sensor faults (current, voltage, and speed). The carried-out simulations and experiments confirm that the proposed sensor post fault-tolerant control approach seems to be effective and provides a simple configuration with high performance in terms of speed response.

\section{Appendix}

EV Mechanical and Aerodynamic Parameters: $m=1540 \mathrm{~kg}$ (two $70 \mathrm{~kg}$ passengers), $A=1.8 \mathrm{~m}^{2}, r=0.3 \mathrm{~m}, \mu_{r r 1}=$ $0.0055, \mu_{r r 2}=0.056, C_{a d}=0.19, G=3.29, \eta_{g}=0.95, v_{0}=$ $4.155 \mathrm{~m} / \mathrm{sec}, g=9.81 \mathrm{~m} / \mathrm{sec}^{2}, \rho=0.23 \mathrm{~kg} / \mathrm{m}^{3}$.
Rated Data of the Simulated Induction Motor: $37 \mathrm{~kW}$, $1480 \mathrm{rpm}, p=2, R_{s}=0.0851 \Omega, R_{r}=0.0658 \Omega, L_{s}=$ $0.0314 \mathrm{H}, L_{r}=0.0291 \mathrm{H}, L_{m}=0.0291 \mathrm{H}, J=0.37 \mathrm{~kg} \cdot \mathrm{m}^{2}$, $k_{f}=0.02791 \mathrm{Nmsec}$.

Rated Data of the Tested Induction Motor: $1 \mathrm{~kW}, 2.5 \mathrm{Nm}$, $2830 \mathrm{rpm}, p=1, R_{s}=4.750 \Omega, R_{r}=8.000 \Omega, L_{s}=0.375 \mathrm{H}$, $L_{r}=0.375 \mathrm{H}, L_{m}=0.364 \mathrm{H}, J=0.003 \mathrm{~kg} \cdot \mathrm{m}^{2}, k_{f}=$ $0.0024 \mathrm{Nmsec}$.

\section{References}

[1] D. U. Campos-Delgado, D. R. Espinoza-Trejo, and E. Palacios, "Fault-tolerant control in variable speed drives: a survey," IET Electric Power Applications, vol. 2, no. 2, pp. 121-134, 2008.

[2] M. E. H. Benbouzid, D. Diallo, and M. Zeraoulia, "Advanced fault-tolerant control of induction-motor drives for EV/HEV 
traction applications: from conventional to modern and intelligent control techniques," IEEE Transactions on Vehicular Technology, vol. 56, no. 2, pp. 519-528, 2007.

[3] M. Zeraoulia, M. E. H. Benbouzid, and D. Diallo, "Electric motor drive selection issues for HEV propulsion systems: a comparative study," IEEE Transactions on Vehicular Technology, vol. 55, no. 6, pp. 1756-1764, 2006.

[4] B. Tabbache, M. E. H. Benbouzid, A. Kheloui, and J. M. Bourgeot, "Sensor fault-tolerant control of an induction motor based electric vehicle," in Proceedings of the 14th European Conference on Power Electronics and Applications (EPE 2011), pp. 1-8, Birmingham, UK, September 2011.

[5] B. Tabbache, A. Kheloui, and M. E. H. Benbouzid, "An adaptive electric differential for electric vehicles motion stabilization," IEEE Transactions on Vehicular Technology, vol. 60, no. 1, pp. 104-110, 2011.

[6] K. S. Lee and J. S. Ryu, "Instrument fault detection and compensation scheme for direct torque controlled induction motor drives," IEE Proceedings, vol. 150, no. 4, pp. 376-382, 2003.

[7] K. Rothenhagen and F. W. Fuchs, "Doubly fed induction generator model-based sensor fault detection and control loop reconfiguration," IEEE Transactions on Industrial Electronics, vol. 56, no. 10, pp. 4229-4238, 2009.

[8] K. Rothenhagen and F. W. Fuchs, "Current sensor fault detection, isolation, and reconfiguration for doubly fed induction generators," IEEE Transactions on Industrial Electronics, vol. 56, no. 10, pp. 4239-4245, 2009.

[9] S. M. Bennett, R. J. Patton, and S. Daley, "Sensor fault-tolerant control of a rail traction drive," Control Engineering Practice, vol. 7, no. 2, pp. 217-225, 1999.

[10] A. Akrad, M. Hilairet, and D. Diallo, "Design of a faulttolerant controller based on observers for a PMSM drive," IEEE Transactions on Industrial Electronics, vol. 58, no. 4, pp. 1416-1427, 2011.

[11] L. Baghli, P. Poure, and A. Rezzoug, "Sensor fault detection for fault tolerant vector controlled induction machine," in Proceedings of the European Conference on Power Electronics and Applications, pp. 1-10, Dresden, Germany, September 2005.

[12] B. Tabbache, M. E. H. Benbouzid, A. Kheloui, and J. M. Bourgeot, "DSP-based sensor fault-tolerant control of electric vehicle powertrains," in Proceedings of the IEEE International Symposium on Industrial Electronics (ISIE'11), pp. 2085-2090, Gdansk, Poland, June 2011.

[13] L. Harnefors, "Instability phenomena and remedies in sensorless indirect field oriented control," IEEE Transactions on Power Electronics, vol. 15, no. 4, pp. 733-743, 2000.

[14] B. Akin, U. Orguner, A. Ersak, and M. Ehsani, "Simple derivative-free nonlinear state observer for sensorless AC drives," IEEE/ASME Transactions on Mechatronics, vol. 11, no. 5, pp. 634-643, 2006. 

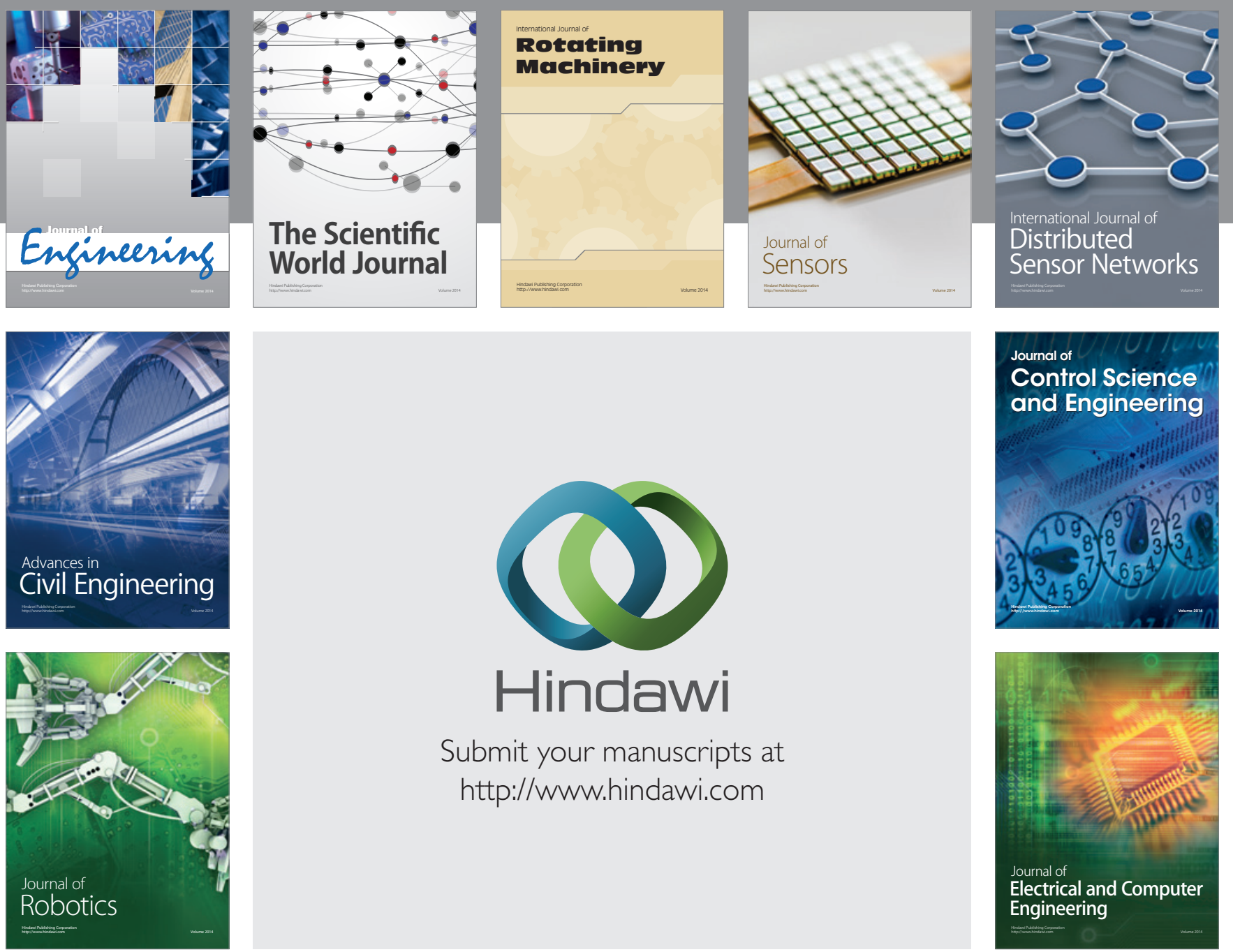

Submit your manuscripts at

http://www.hindawi.com
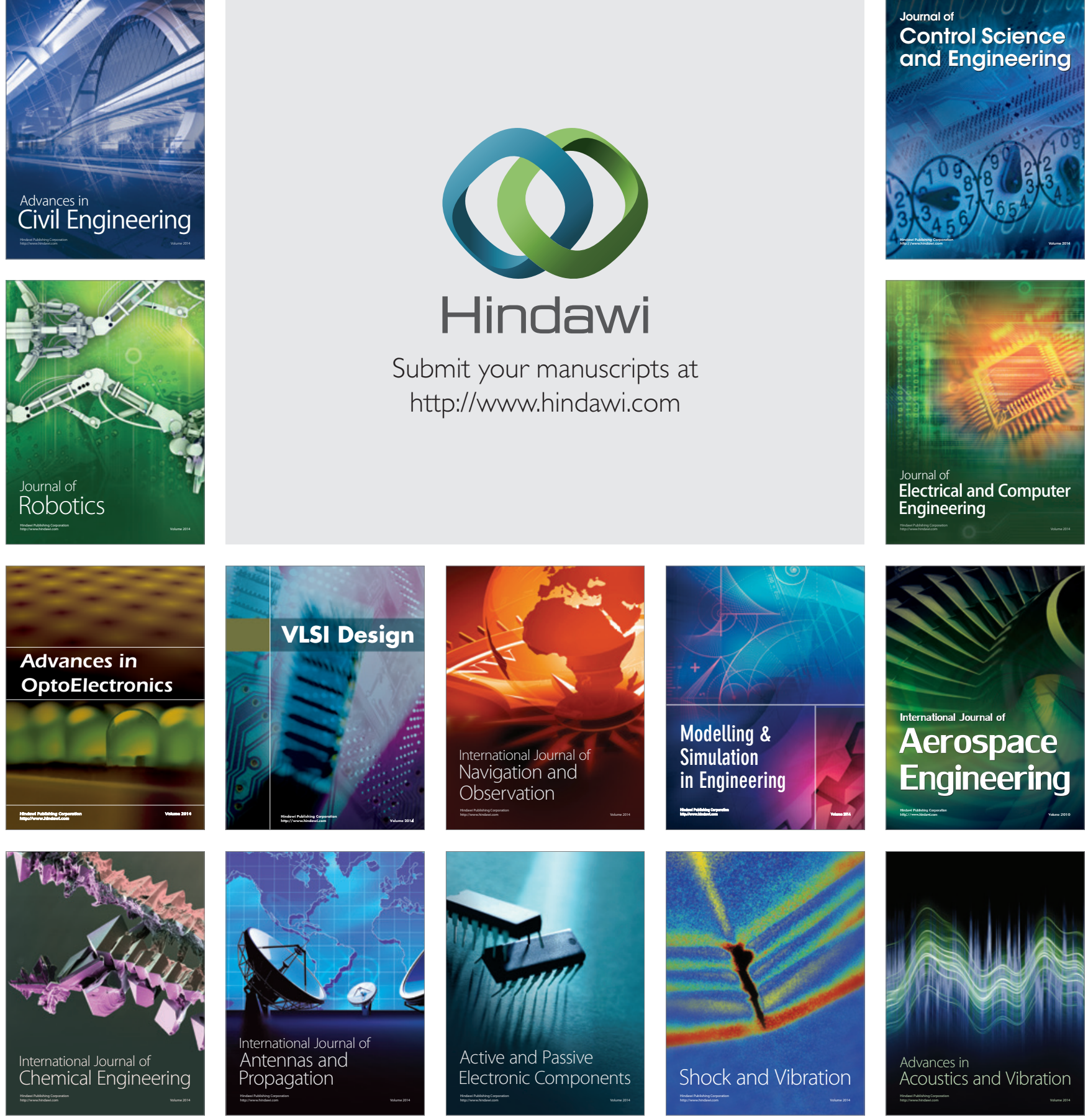